\title{
A Real-time Products Management Method in Supply Chain Management based on IOT
}

\author{
Xindan ZHAO \\ College of Information Science and Engineering, Northeastern University, Shenyang 110004, China \\ Jihong LIU \\ College of Information Science and Engineering, Northeastern University, Shenyang 110004, China \\ E-mail: liujihong@ise.neu.edu.cn \\ Xue SUN \\ College of Information Science and Engineering, Northeastern University, Shenyang 110004, China
}

\begin{abstract}
Supply chain management is becoming the core competitiveness in enterprise competition, which is an important way to increase the enterprise's profitability. With the development of the Internet of Things, supply chain management is gradually achieved by information technologies. This paper studies an information-based real-time products management method in supply chain management system through Java language, XML and other information technologies. Firstly, we introduce the supply chain management, then using XML document and B/S structure to realize the electronic management for products during product circulation process. The experimental results show that this system is stable and practicable, and could efficiently collect the product flow information which could provide valuable information for the materials and manufacture enterprises.
\end{abstract}

Keywords supply chain management; the Internet of Things; B/S structure; XML document

\section{Introduction}

In this era of rapid development of information technology, with the rapid popularization of internet, all kinds of new technology constantly affect our life and improve people's quality of life and work efficiency. As an important part of the emerging technologies, the Internet of Things (IOT) describes a world where humans are surrounded by the uniquely identifiable objects that communicate with each other and can allow people to interact with the digital world $^{[1]}$.

Nevertheless, IOT should not only be considered from a technical perspective, but also should be seen as commercial services that satisfy consumers' need ${ }^{[1]}$. To a certain degree, the development of IOT has promoted the information construction of enterprise. A simple and efficient information management method is considered to be an effective means to improve the competitiveness of enterprises.

Radio frequency identification (RFID) - a kind of non-contact auto identification technology. Things by using RFID can be identified, and the relevant data can be obtained without

Received December 11, 2013, accepted February 21, 2014 
manual interference and can be used in all kinds of adverse environment. Table 1 shows the components of the IOT-based EPC system. It can greatly enhance the monitoring level for production, distribution and storage bunker ${ }^{[2]}$.

Table 1 The components of the EPC system

\begin{tabular}{lll}
\hline System Components & Name & Node \\
\hline EPC system & EPC standard & $\begin{array}{l}\text { Identify the specific code of a single } \\
\text { product }\end{array}$ \\
\hline RFID system & EPC tag; Reader & $\begin{array}{l}\text { Be attached to the goods or embed- } \\
\text { ded in articles; Read EPC tags }\end{array}$ \\
\hline $\begin{array}{l}\text { Information network } \\
\text { system }\end{array}$ & $\begin{array}{l}\text { EPC savant; ONS (Object Naming } \\
\text { Service); PML (Physical Markup } \\
\text { Language) }\end{array}$ & $\begin{array}{l}\text { The software support system of EPC } \\
\text { system; Position the corresponding } \\
\text { information of goods; Describe the } \\
\text { information of goods }\end{array}$ \\
\hline
\end{tabular}

At present, a large number of distributors across the country, the constantly extended supply chain makes all levels of management difficult to obtain accurate demand information of product. Therefore, how to optimize the supply chain and improve the operating efficiency in every link becomes a major problem for all enterprises and distributors. Successful supply chain management depends on tight coordination between supply chain partners. The internet provides the perfect communications channel for the information, decisions, transactions, and processes that form supply chain management ${ }^{[3]}$. Through the IOT technology, we can develop an information-based products supply chain management system, which makes the distributors at all levels can share the flowing information, and grasp the market fluctuations accurately, then improve the whole benefit of corporations.

After researching the current supply chain management status, this paper designs a supply chain management system through the technology of RFID, Java and XML, which realize the electronic management of product during the whole process.

The rest of this paper is organized as follows. Section 2 presents the analysis of the supply chain management status. Section 3 contains five parts, presents the designs and realization of system including overall design of system, design XML document, collect product information, and stock management, as well as some application examples. The last part is the conclusion of this paper.

\section{Analysis of the supply chain management status}

A supply chain is a network of facilities and distribution options that performs the functions of procurement of materials, transformation of these materials into intermediate and finished products, and the distribution of the finished products to customers ${ }^{[4]}$. Nowadays, supply chain management has become a dominant theme in the research of operations management. Successful supply chain management depends on tight coordination between supply chain partners ${ }^{[3]}$. For a long time, our products supply chain uses the following mode: "materials suppliermanufacturer - multi-level distributors - retail terminals - end consumers" ${ }^{[5]}$. Figure 1 shows the sale process for one product, and it also shows the supply chain activities. 


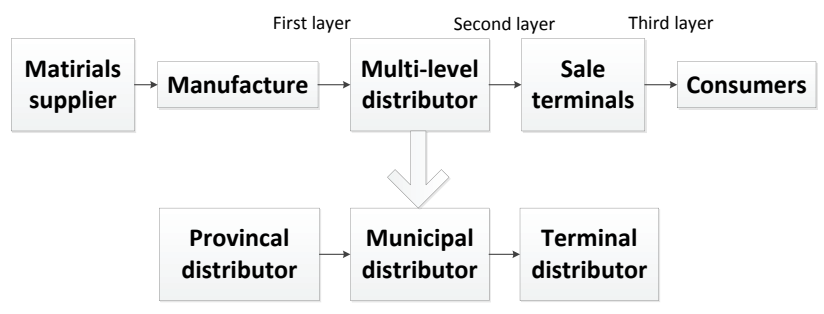

Figure 1 Flowchart of product sales

Obviously, this is a marketing model with high center of gravity, and each part along the supply chain operates independently, which appearing funnel type from upstream to downstream. It means that the upstream customers are always larger than the downstream customers ${ }^{[5]}$. Each nodal distributor needs to determine the demands based on the orders from downstream distributors, and to forecast the demands for the next period. But such predictions are mostly depends on intuition and experience, lack of in-depth analysis of historical business data and current market conditions, another problem is that the enterprises in supply chain lack of sharing the forecast information, which result in the increase of overall stock in supply chain, excess production capacity, make the burden on enterprises much heavier ${ }^{[6]}$.

In addition, because of all level distributors need to set the safety stock, a problem arises in the supply chain system: the market demand was forecasted repeatedly, and this forecast volatility constantly enlarges as the increase of the level, so the "Bullwhip Effect" arise ${ }^{[7]}$. The "Bullwhip Effect" (BWE) refers to the phenomenon that order variability increases as orders move upstream along the supply chain ${ }^{[8]}$. The BWE can eventually lead to excess inventory as well as unused or overused capacity. It dramatically increases the operating costs of the supply chain system and often leads to serious supply and demand mismatches and deterioration in customer service levels ${ }^{[8]}$. This effect will be more serious if it has a longer supply chain, and the terminal sales data will be less clear. Therefore, how to optimize the supply chain and reduce bullwhip effect becomes a major problem for all enterprises and distributors. Experience suggests that the most intuitive response to the BWE is some form of information sharing to help coordinate the supply chain. Without forecast updating there is no BWE, information sharing is the most direct way to reduce the $\mathrm{BWE}^{[8]}$.

With the development of science and technology, information technology continues to improve our lives. The internet gives the part along supply chain a new perfect communication channel. As Radio-frequency identification (RFID) technology is now prevalent, several major retail chains have strongly promoted, or even mandated, RFID adoption by their suppliers, mostly at the pallet level ${ }^{[9]}$. RFID is an integrated circuit with an antenna, which can be attached to any product and package. RFID technologies have been shown to be very useful in production planning, transportation, and warehousing ${ }^{[10]}$. And it is being discussed as a powerful means to solve the problem of inventory uncertainty, among a plethora of other problems in supply chain execution ${ }^{[9]}$. Typically there is a silicon chip in RFID tag, and it can contain a certain amount of data as the form of a unique identification number. It uses scanners to read the labels, and then rely on an IT system that cross-references the ID on the label and relates it to an object or a class of objects using a database system ${ }^{[11]}$. Take retail giants Walmart as an 
example, RFID has been adopted several years for use by supply chain management. Products can be tagged with RFID chips at the factory. Merchandises are typically tagged chips at the color, size and another aspects ${ }^{[12]}$. So buyer can ensure the products' identity and validity.

In conclusion, we can scan the product label to obtain its circulation information, and then pass it to the networked information sharing platform, realizing effective and visual supply chain management, which finally soothe market stress and increase business efficiency to some extent. The whole system is sustainable from both theoretical and actual perspectives ${ }^{[13]}$.

\section{Designs and realization of system}

\subsection{Overall design of system}

Java web development provides two modes: B/S (Browser/Server) structure and C/S (Client/Server) structure. With the development of internet technology, B/S structure is an improvement of $\mathrm{C} / \mathrm{S}$ structure. $\mathrm{B} / \mathrm{S}$ is established on the basis of WAN (Wide Area Network) and manages the information by itself which has stronger adaptation scope than $\mathrm{C} / \mathrm{S}$. The client access the server through browser, realize the information interaction and sharing, dynamic configure WEB server and application server by the traffic ${ }^{[14,15]}$. According to the application scale and the content of this system, and the code reusability, system extended and maintenance, we adopt B/S development mode.

The system uses RFID tags to give each product a unique code, uses PDA (Personal Digital Assistant) to scan the tag and records its information as an XML document, Extensible Markup Language document, then sends it to the host computer. The host computer is a stock management system that adopts B/S structure. It receives and parses the XML document, then sends the information to the data server through the encrypted VPN tunnel. The end users can search and statistic the information from database. As shown in Figure 2 is the total structure of the system.

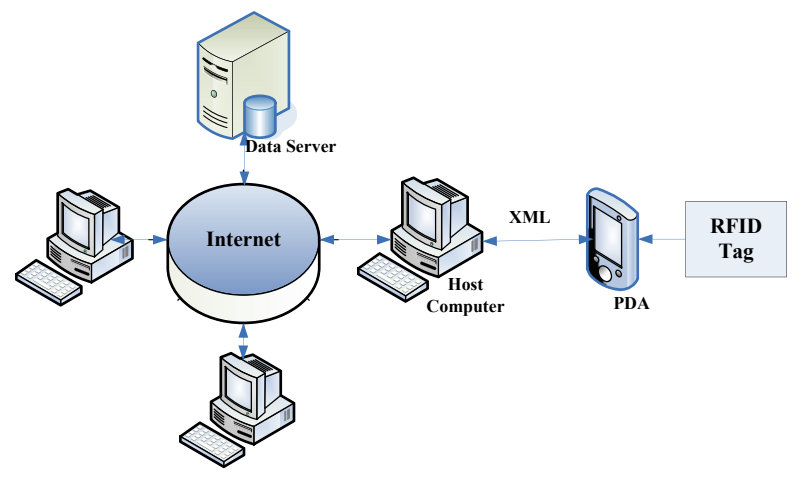

Figure 2 Total structure of the system

\subsection{Design of XML document}

XML is launched in 1998 by W3C (the World Wide Web Consortium), which is the criteria for data exchange and representation on the internet ${ }^{[16]}$. XML has become a key technology for data integration and exchange, which is independently of any application domain. XML technology has strict standards, and features concise and scalable expand. The role it plays has been more and more important in the data exchange on the Web and elsewhere ${ }^{[17]}$. XML 
technology focuses on data, it acts as the media of data transfer in network application, which solved the problems like display, formatting, document manipulation and provided favorable conditions for programmer to develop highly efficient software system.

Indeed, it is primary to match the schema between XML document and the database during transfer data from XML documents to a relevant database. Since the structure of the XML documents may not exactly match the structure of the existing database, we generate an XML schema of the relational database before carrying out the mapping process ${ }^{[17]}$.

In order to trace the product throughout the whole distribution system, we given each product an associated XML document which records the product number, name, specification and other specific information when at the factory, so only operate on the product number to inquiry related information in the whole process of circulation. In this system, the structure and node meaning of the associated XML is shown in Table 2.

Table 2 The structure and node meaning of associated XML

\begin{tabular}{|c|c|c|}
\hline Node Name & Node Meaning & Node Property \\
\hline Document & the root node & License: required \\
\hline Events & $\begin{array}{l}\text { the child node of Document; appear } \\
\text { only once }\end{array}$ & $\begin{array}{l}\text { Version: version number, default is } 3.0 \text {, op- } \\
\text { tional }\end{array}$ \\
\hline Event & $\begin{array}{l}\text { the child node of Events; can ap- } \\
\text { pear multiple time; distinguish the } \\
\text { incident }\end{array}$ & Name: incident name, required \\
\hline Relation & $\begin{array}{l}\text { the child node of Event; define the } \\
\text { product information }\end{array}$ & $\begin{array}{ll}\text { Product Code: required; package: re- } \\
\text { quired; cascade: required; comment: op- } \\
\text { tional }\end{array}$ \\
\hline Batch & $\begin{array}{l}\text { the child node of Relation; define } \\
\text { the batch number, made date and } \\
\text { so on }\end{array}$ & $\begin{array}{l}\text { Batch No: required; made Date: required; } \\
\text { validate Date: required; work Shop: re- } \\
\text { quired; line Name: required; line Manager: } \\
\text { required }\end{array}$ \\
\hline Code & $\begin{array}{l}\text { the child node of Relation; define } \\
\text { specific product code and package } \\
\text { property }\end{array}$ & $\begin{array}{l}\text { Cur Code: required; Pack Layer: required; } \\
\text { Parent Code: optional }\end{array}$ \\
\hline
\end{tabular}

From the Table 2, we can see that the associated information of each product is completely recorded and the product code is unique. When the product be placed into storage or removed from storage, using PDA to scan each product to get its number, then create the circulated XML document combine with the type of operation. In this system, define the structure and node meaning of the circulated XML as Table 3.

\subsection{Collection of product information}

This system uses the PDA (Personal Digital Assistant) to scan the product, get the label coding, and combine them into a XML file. The development of PDA machine based on the VS2005 platform, and uses the C\# language. Achieve the save of date and the creation of XML file at the same time. Through setting the IP address of target PC machine, the system can connect to the PC machine automatically and finish the communication of data. This device 
Table 3 The structure and node meaning of circulated XML

\begin{tabular}{|c|c|c|}
\hline Node Name & Node Meaning & Node Property \\
\hline Document & the root node & License: optional \\
\hline Events & $\begin{array}{l}\text { the child node of Document; appear } \\
\text { only once; distinguish the data of } \\
\text { different incident }\end{array}$ & Comment: optional \\
\hline Event & $\begin{array}{l}\text { the child node of Events; define the } \\
\text { action of current incident }\end{array}$ & $\begin{array}{l}\text { Name: optional; Main Action: required; } \\
\text { Comment: optional }\end{array}$ \\
\hline $\begin{array}{l}\text { Action Map- } \\
\text { ping }\end{array}$ & $\begin{array}{l}\text { the child node of Event; define the } \\
\text { data of current incident }\end{array}$ & \\
\hline Action & $\begin{array}{l}\text { the child node of Action Mapping; } \\
\text { can appear multiple time; define the } \\
\text { data of each action }\end{array}$ & Name: required \\
\hline Action Data & $\begin{array}{l}\text { the child node of Action; can ap- } \\
\text { pear multiple time; define the data } \\
\text { name of this action }\end{array}$ & $\begin{array}{l}\text { Code: required; Corp Order ID: required; } \\
\text { Actor: required; Act Date: required; From } \\
\text { Corp ID: optional; To Corp ID: optional }\end{array}$ \\
\hline Data Field & $\begin{array}{l}\text { the child node of Event; conclude } \\
\text { the specific data }\end{array}$ & \\
\hline
\end{tabular}

includes 5 function models: system setting, data communication, in-storage, out-storage, and data deletion. The main interface of the device is shown in the Figure 3.

Data communication includes warehousing order upload and outbound order upload, which can achieve the wireless transmission of data. Firstly, the user needs to set the IP address of PC that you want to connect with. The system will call the corresponding host, and then upload the storage bunker order or departure order.

After entering the interface of in-storage or out-storage, we need to input the number for two times, and then getting into the scan interface. If prompted this number "has executed put into storage/remove from storage scan", then we need to choose "add record" or "resume", as it is shown in Figure 4. When all products in the current list have been scanned, click the "done" batten to save the scanned data. The device will combine out a XML for these operate according to the information such as operator and operate type, and store it at a specified position.

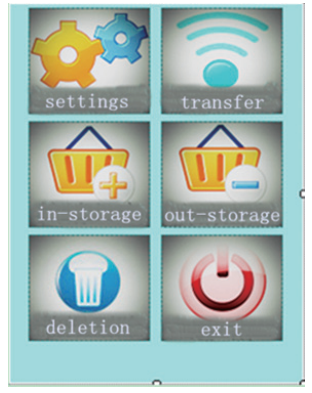

Figure 3 The main interface of the PDA

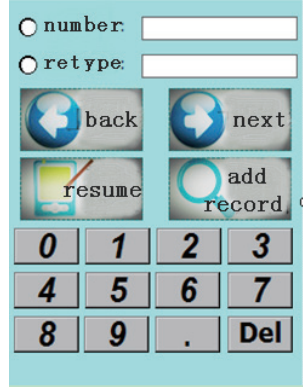

Figure 4 The interface of in-storage or out-storage 


\subsection{Stock management system}

(1) Development Language and Pattern

The stock management system in the host computer uses java program language and Struts 1.2 framework, develop and debug in My Eclipse. The design of this system is as follows: the display layer of foreground use JSP and Servlet to realize on a browser (e.g. Internet Explorer, Chrome), the middle part realize the business logic of enterprises by using the Java Bean module, and the background achieve the users demand and interrelated jump operations by using the action layer. To sum up, the system adopts a three-layer B/S structure which benefits the application logic implementation, maintenance and update ${ }^{[14]}$. In order to accelerate data storage and query, we choose SQL Server 2008 database which offers many Web and ecommerce capabilities, and then use JDBC to set up the connection with system. As shown in Figure 5 is the structure of system development pattern ${ }^{[18]}$.

The struts framework is a kind of MVC design patterns, which uses Servlet and JSP mark as tools to realize the design. Struts framework not only inherits MVC design patterns, but also makes corresponding changes and expansion according to the characteristics of the J2EE ${ }^{[19]}$. Java platform provides the basis for securely and easily spread the code on the network, and XML technology provides the same capability for data, which is a clear and independent way of representing content. The combination of the two makes programmers can quickly develop a standard application with independent platform. XML and Java technology are very generally on the using of exchange information on the network system, such as electronic data interchange, e-commerce and so on ${ }^{[20]}$.

The system uses JDOM to parse XML documents. JDOM (Java Document Object Model) is a unique Java toolkit, which using for parse, create and serialize XML document. It availably integrate the advantage of SAX and DOM, not only can rapidly analyze and export document like SAX, but also expedient like DOM. It is a simple and lightweight method of operating XML documents ${ }^{[15]}$.

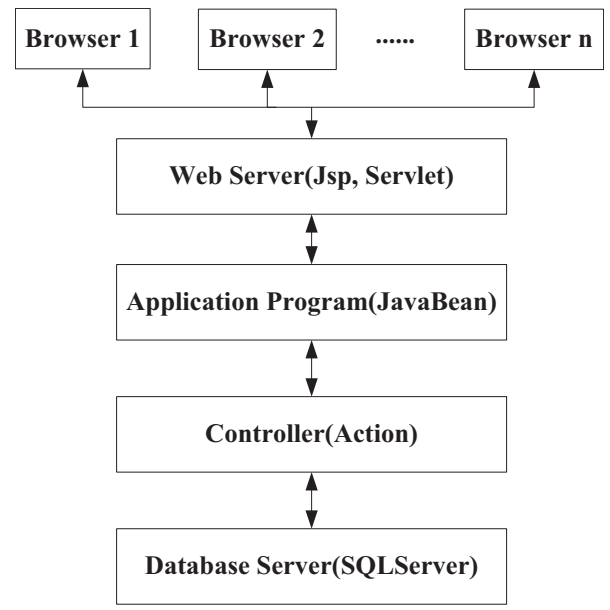

Figure 5 Structure of development pattern

(2) Structure of Stock Management System

Looked from the demand functions, this system mainly include four kinds of user and 
five modules. The four kinds are general administrator, provincial administrator, municipal administrator and distributor administrator. Different user has different management rights and sub-functions. The general administrator has the highest rights among them which can manage every distributor and product, including related query, add, delete, audit and so on. The five modules are user login module, inventory information management module, distributor information management module, drug information management module, user information management module, data transmission module. The principle diagram of system function is displayed in Figure 6.

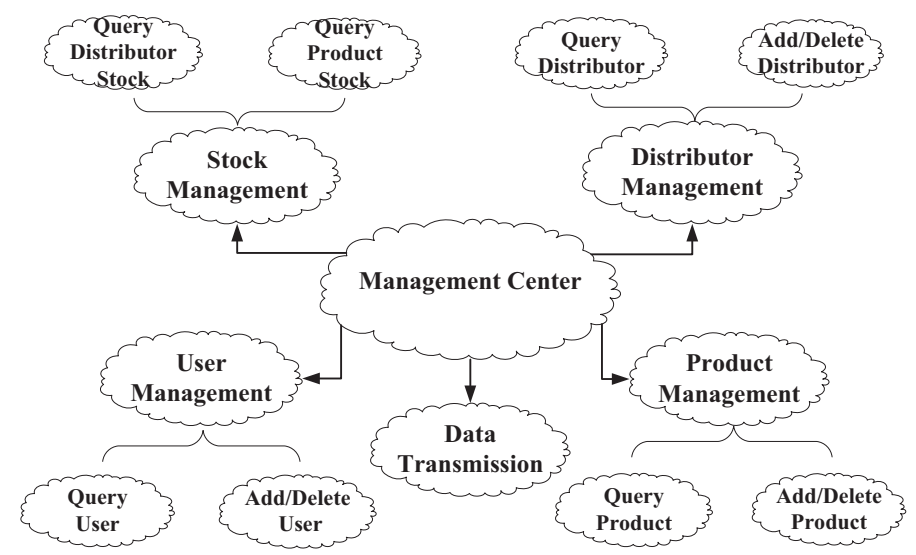

Figure 6 Schematic diagram of stock system function

The interface of stock query uses cascading drop list, which realized dynamic link through java script technology. It can display the real-time information in database for users to choose. The system makes statistics depend on product code and shows as tabular form for users to view and analysis. In consideration of the real-time changes of stock-sheet data, the interface provides dynamic refreshing function by using Ajax technology. Ajax means asynchronous JavaScript and XML, and is mainly used in locally refreshing of web page, and the whole page will not change as user's request each time, which greatly improve the program's performance. In Ajax, sending and response of asynchronous requests are managed by the XML Http Request object. Firstly, it needs to confirm the type of using internet explorer. Secondly, it needs to create an appropriate XML Http Request object to call the specified method. Finally, it uses JavaScript to set the content to specified display region ${ }^{[21]}$.

\subsection{Application example}

As pharmaceutical industry (PI) strongly relates to public health and safety of patients, proper management of information is of great importance in drug circulation process. There are so many organizations are active in this field: World Health Organization, Uppsala Monitoring Care, Council for International Organizations of Medical Sciences and so on ${ }^{[12]}$. Our government and society also attach great importance to drug supply chain ${ }^{[1]}$. So we take the example of drug supply chain, to introduce the application of this system.

In 2007, the Chinese State Food and Drug Administration proposed a constructive management model Drug electronic supervision code (known as drug code), by this way to strengthen the supervision of drug circulation. Just like an ID card, it gives every product a unique code. 
This code is an implement to realize the dynamic monitoring of the drug production, the product logistics, the marketing and other fields, to guarantee the traceability and authenticity of medicines in every procedure ${ }^{[22]}$. Drug electronic supervision code is composed by 20 digits, and associated with $14 \mathrm{drug}$ standard codes shows in Table 4.

(1) Pharmaceutical flag bit is one number defined as " 8 ".

(2) Pharmaceutical product code is composed of six numbers, deliver the information of drug production enterprise and drug information. Regulatory platform automatically assigned product code for each packing specification.

(3) Pharmaceutical code number is composed of nine numbers which have described each individually packaged drugs.

(4) Each drug electronic supervision code is valid for ten years.

Table 4 Encoding rules of drug electronic monitoring code

Flag bit-1 number Product code-6 numbers Code number-9 numbers Captcha-4 numbers

Based on the implementation of drug electronic supervision code, we can apply our system on drug management. Firstly, after obtaining a code's scanning information, the PDA transfers the XML document to the host computer. Secondly, the corresponding host analyzes it and modifies the database. Finally, the system judges its state depends on the database and then comprehensively collects the accurate inventory information without missing and confusing.

According to the demand of drug stock management system, we designed the structure of information sheet in database as Figure 7. Every data table establishes the relationship with others through different columns, to achieve the associated query in multiple tables.

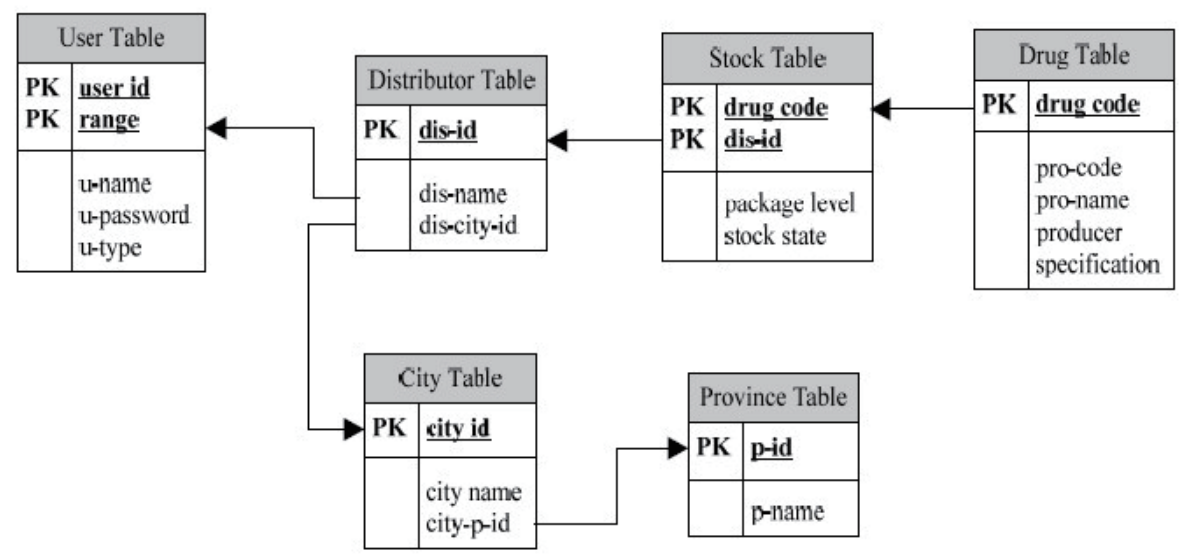

Figure 7 Diagram of drug database

(1) Drug-Stock-Distributor

After received the data information from XML, the system search the corresponding product code, packaging level etc. in drug information table, at the same time retrieve the stock information table and modify the corresponding stock state or add a new record.

When user queries the stock information, the system retrieves the stock information table according to the selected user ID to find all of the drug stock state information. System classifies 
them by the product code and statistics the number of each packaging level, then displays them for user to view.

(2) User-Distributor

The type and manage scope are stored in the user table. When a user login, the system will jump to different main interface according to the user's type and display different manage function according to the user's manage scope. Each distributor can have only one administrator and each administrator can manage only one distributor, no repeated.

(3) Distributor-City-Province

The distributor information table, city information table and provincial information table constitute a three-level drop list for user to select. The Province information table store up all of the city's name and number, the city information table include one more column that is its province number, and the distributor information table also has a column to store up its city number, which make the three tables constitute a cascading query.

User interface should be simple and precise, so that the structure and usage of the system are clear at a glance to users. The system main interface is divided into three parts: head page, welcome page, menu page. Firstly, the head page contains title, date and back up operation. It is also read the current login user name which is keep unchanged through the whole system operation. Secondly, the welcome page show the welcome words. When the user selects different functions the interface switches to the corresponding module interface. Thirdly, the menu page displays the system function of all menu items. Because the function permissions are not identical, different type user have different menu options. We realize the connection menu at all levels by using Java script in the tree structure.

It is can be seen that this system can greatly improve the efficiency and accuracy of the drug stock management. It realized the real-time electronic management for drugs and optimized the drug supply chain.

\section{Conclusion}

Informatization of the supply chain management system is the necessary way for the future development of all enterprises. This paper has studied the status of supply chain management, then developed and realized a supply chain management system combined with XML, Java and other technology, and it pays attention on the real-time product information management in product circulation. Different enterprises can improve the system according to their own condition. It is observed that this system is stable and practicable, and could efficiently collect the product flow information which could provide valuable information for the materials and manufacture enterprises. Overall, the proposed scheme enables our life to be more systematic and efficient.

\section{References}

[1] Liu L R, Jia W. Business model for drug supply chain based on the internet of things. The 2nd IEEE International Conference on Network Infrastructure and Digital Content, Beijing University, Beijing, 2010.

[2] Gu Y, Jing T B. The IOT research in supply chain management of fresh agricultural products - Artificial Intelligence. 2011 2nd International Conference on Management Science and Electronic Commerce (AIMSEC), 2011: 7382-7385. 
[3] Harper R L, Jr. Warehouse technology in the supply chain management systems. The 2010 Annual Reliability and Maintainability Symposium, Florida Institute of Technology, Florida, 2010.

[4] Modarres M, Nazemi J. Robust supply chain coordination modeling: A revenue management perspective. Journal of Industrial Engineering International, 2009, 5(9): 1-16.

[5] Xu Y Y. Drug distribution goes to diversification. Medicine Industry, 2005, 1: 54-56.

[6] Fang L. Inventory management of fast moving consumer goods in supply chain. Beijing Jiaotong University, 2010.

[7] Yang Y J. Analysis and research on the bullwhip effect theory in supply chain. Chang'an University, 2009.

[8] Kouvelis P, Chambers C, Wang H Y. Supply chain management research and production and operations management: Review, trends, and opportunities. Production and Operations Management, 2006, 15(3): 449-469.

[9] Heese H S. Inventory record inaccuracy, double marginalization, and RFID adoption. Production and Operations Management, September-October 2007, 16(5): 542-553.

[10] Choi T M. Coordination and risk analysis of VMI supply chains with RFID technology. IEEE Transactions on Industrial Informatics, 2011, 7(3): 497-504.

[11] Gaukler G M, Seifert R W. Applications of RFID in supply chains — Trends in supply chain design and management. Springer Series in Advanced Manufacturing, Part I, 2007: 29-48.

[12] Wigand R T, Mande D M, Wood J D. Information management and tracking of drugs in supply chains within the pharmaceutical industry. 2011 Eighth International Conference on Information Technology: New Generations (ITNG), 2011: 500-507.

[13] Nee A Y C, Song B, Ong S K. The analysis of sustainable supply chain management. Proceedings of the 20th CIRP International Conference on Life Cycle Engineering, Singapore, 2013: 17-19.

[14] Zhu X, Ling Y S, Yang Y L. Design and implementation of information management system for multimedia classroom based on B/S structure. Frontier and Future Development of Information Technology in Medicine and Education, 2014: 2221-2231.

[15] Zheng H A, Yu D W. Information management system of skills training based on B/S structure. Proceedings of the 2012 International Conference on Communication — Electronics and Automation Engineering, 2013: 0741-0746.

[16] Li H A. Research on design methods and normalization of XML. Northwest University, 2009.

[17] Jumaa H. An XML-based framework for automating data exchange in healthcare. 2010 12th IEEE International Conference on e-Health Networking - Applications and Services, 2010: 264-269.

[18] Sun H L. The development and implementation for the purchase-sale-storage system of pharmaceutical companies based on J2EE. Ocean University of China, 2009.

[19] Yang J, Li L X, Liu Z Q, et al. Management system for scientific research projects based on the combined framework of struts and hibernate. 2011 2nd International Conference on Artificial Intelligence, Management Science and Electronic Commerce (AIMSEC), 2011.

[20] Pan D L. Research and application of the Internet data exchange based on Java and XML. Dalian Jiaotong University, 2009.

[21] Li X H, Wang Y Q. The classic combat of Java web developing. Tsinghua University Press, 2010: 417-427.

[22] Feng J Q, Shu M. Combination of the drug electronic supervision code system and the pharmaceutical packing process. Mechanical and Electrical Information, 2009, 26: 47-49. 